International Journal of Production Research

Volume 54, Issue 8, pp 2345-2365

DOI:10.1080/00207543.2015.1076944

\title{
Applying Performance Measures to Support Decision-making in Supply Chain Operations: a Case of Beverage Industry
}

\begin{abstract}
Performance Measurement Systems (PMS) have commonly been applied to evaluate and reward performances at managerial levels, especially in the context of supply chain management. However, evidence suggests that the effective use of PMS can also positively influence the behaviour and improve performance at an operational level. The motivation is to accomplish organisational goals, namely to increase supply chain flexibility by responding to evermore-varying customer demands in a timely manner. The purpose of the study described in this paper is to develop a conceptual framework that adopts performance measures for ex-ante decision-making at an operational level within the supply chain. To guide the research, five questions were asked and subsequently key gaps have been identified. In an attempt to fill the gaps, a case study at a major global brand beverage company has been carried out, and as a result, a conceptual framework of the performance measurement system has been developed. Overall, the research offers a foundation of the applicability and impact of PMS in the supply chain and provides a framework that attends to some of the potential uses of PMS that so far have not been practically applied. The outcomes from the testing indicate that the initial gaps identified in the literature have been addressed and that the framework is judicious with scope for practical applicability. The framework is deemed worthy of further testing in different operational contexts of the supply chain
\end{abstract}

Keywords: Performance measures, Performance Measurement Systems, Supply Chain Operations, Decision-making, Flexibility

Published by Taylor and Francis. This is the Author Accepted Manuscript issued with: Creative Commons Attribution Non-Commercial License (CC:BY:NC 3.0).

The final published version (version of record) is available online at DOI:10.1080/00207543.2015.1076944. Please refer to any applicable publisher terms of use. 


\section{INTRODUCTION}

Research in the field of performance measurement has drawn on a variety of disciplines, from production and operations management to accounting and management control. Even though the use of Performance Measurement Systems (PMS) is common amongst managers when defining and evaluating the success of strategic goals (Gomes et al., 2011), the equivalent cannot be said for the use of the same systems as ex-ante ${ }^{1}$ support tools to drive performance (Grafton et al., 2010). Furthermore, although research suggests that PMS can positively influence individuals at an operational level, there is little evidence showing how it works in practice. As a consequence, individuals require the right information, at the right time, in the right format and at the right cost, and meeting these requirements remains a challenge (Schuff et al., 2010).

The innovation of performance measurement can benefit organisations through the delivery of strategically aligned metrics that facilitate decision-making. Providing decision support frameworks and tools that integrate multiple measures in the evaluation process may reinforce the importance of these measures and thus enhance their efficacy in relation to strategic goals (Franco-Santos et al., 2012). Recent research suggests organisations have to be flexible in adapting to frequent changes in customer demand especially in fast moving industries (Poon et al., 2011). Adjustments to production system have to be considered within short time periods, and as a consequence, operational level employees are often being empowered to make decisions and take subsequent actions.

From the literature and observation it has been found that decision-making processes tend to be based either on expert knowledge and little accurate data, or alternatively made by IT systems (e.g. decision support systems), using complex algorithms that provide employees with the answers (Chapman and Kihn, 2009). The main limitation in the former is that individuals are not making informed decisions, and in the latter, psychological empowerment is being confined, consequentially tending towards reduced motivation and capacity to solve problems.

Taking these factors into consideration, the goal of the study described in this paper is to increase supply chain flexibility by enabling individuals at an operational level to respond to

1 Ex-ante means that a decision results in an outcome, as opposed to making a decision based on the outcome of an action. 
variations in customer demand whilst considering the overall impact on the supply chain. To achieve this goal, a framework that enables the informed ex-ante decision-making has been proposed. The framework utilises the performance measurement system as the main driver of the decision-making process within the supply chains. The framework has been tested at the case company's manufacturing facility focusing on the Production Planning department.

This paper is structured as follows. Having laid down the industrial context of the research, a systematic literature review was conducted to better understand the extent to which the issues have been addressed in the literature. The paper then discusses the research methodology adopted before the detailed account on the development and testing of the framework. The paper ends with some concluding remarks detailing both the strengths of the contributions and the future work that needs to be pursued.

\section{LITERATURE REVIEW}

The literature review has been conducted by following a four-step process. First, the research boundaries were scoped and research questions were constructed. Following a summary of key findings based on relevant literature, the gaps in the body of knowledge, hence the justification of the research, were identified.

\subsection{Aim, Scope and Research Questions}

As mentioned before, the main aim of the literature review is to understand state-of-the-art Performance Measurement Systems (PMS) and to establish the current uses of PMS in industry. The scope of the review was therefore bounded by PMS uses, applicability and impacts. Well known PMS, such as the Balanced Score Card (Kaplan and Norton, 1992),

performance measurement questionnaires (Dixon et al., 1990), ECOGRAI (Bitton, 1990) and Policy Deployment (hoshin kanri) were first consulted. The details of the performance measures that comprise the PMS have, however, deliberately been kept out of scope. The intent was to focus on the potentials that PMS offer irrespective of the performance measures themselves. To accomplish this, the following research questions were constructed.

1) What are the typical uses of PMS?

2) Who is affected by PMS?

3) How do PMS impact performance?

4) How do PMS influence decision-making? 
Being aware that the literature may not fully contain the required details for a complete illumination on the subject, the intention of such questions was solely to guide the research.

\subsection{Search strategy}

The search strategy was initially developed by identifying the relevant databases, including journals, books, and conference proceedings as part of the document library. The primary search engine was Web of Knowledge, Thomson Reuters and included databases such as ABI/Inform, Emerald, IEEE Xplore, and Scopus. The time frame was confined from 2006 to 2015. Keywords such as "performance measurement”, “decision-making”, "supply chain” "strategic", "operations", "operational" and their combinations were then applied to focus on the relevant information. To capture associated concepts, other keywords were added to encompass decision-facilitating and decision-influencing roles of PMS, traditional and contemporary PMS, supporting technology, impact on performance, and different organisational levels. Having considered the entire search strings used, there were 2384 papers retrieved. By cross-checking, time-frame filtering and removing redundancy, the papers were dramatically reduced to 273 . By reading the abstracts, the scope of each paper was checked and eventually the majority of the papers were excluded, leaving 28 papers deemed relevant and suitable for review. Judging from the abstracts, these papers demonstrated their relevance to our research questions above, in particular the decisionfacilitating and decision-influencing roles. These papers were then analysed and reviewed in detail. Table 1 shows the excerpts from the papers described in a format that shows both the purposes and key findings of each paper. 
Table 1: Key publications identified

\begin{tabular}{|c|c|c|c|c|}
\hline No & Author & Purpose & Key findings & Source \\
\hline 1. & $\begin{array}{l}\text { Angerhofer and } \\
\text { Angelides (2006) }\end{array}$ & $\begin{array}{l}\text { The paper aims to model the constituents, key } \\
\text { parameters and performance indicators of a } \\
\text { collaborative supply chain, and demonstrate in a } \\
\text { case study how to incorporate these into a } \\
\text { decision support environment. }\end{array}$ & $\begin{array}{l}\text { Modelling the components, the key parameters, and the } \\
\text { appropriate performance measures of a collaborative } \\
\text { supply chain allows better understanding of the impacts } \\
\text { from changes in these components and key parameters to } \\
\text { the collaborative supply chain. }\end{array}$ & $\begin{array}{l}\text { Decision Support } \\
\text { Systems }\end{array}$ \\
\hline 2. & $\begin{array}{l}\text { Shepherd and } \\
\text { Günter (2006) }\end{array}$ & $\begin{array}{l}\text { This is a literature review paper that attempts to } \\
\text { address the lack of research into performance } \\
\text { measurement systems and metrics of supply } \\
\text { chains, and suggests a number of avenues for } \\
\text { future research. }\end{array}$ & $\begin{array}{l}\text { Despite considerable advances in the literature in recent } \\
\text { years, a number of critical issues have not yet received } \\
\text { adequate attention. These include: (1) the factors affecting } \\
\text { the successful implementation of supply chain performance } \\
\text { measurement systems; (2) the forces shaping their } \\
\text { evolution over time; and (3) the problems of maintenance. }\end{array}$ & $\begin{array}{l}\text { Journal of Productivity } \\
\text { and Performance } \\
\text { Management }\end{array}$ \\
\hline 3. & $\begin{array}{l}\text { Berglund and } \\
\text { Karltun (2007) }\end{array}$ & $\begin{array}{l}\text { The paper presents a study of scheduling work } \\
\text { that addresses how the production-scheduling } \\
\text { processes in practice are influenced by human, } \\
\text { technological, and organisational aspects. }\end{array}$ & $\begin{array}{l}\text { The successful scheduling process is influenced by at least } \\
3 \text { components: (1) the scheduler incorporating human } \\
\text { capabilities that cannot be automated; (2) technical } \\
\text { constraints in the scheduled production system and (3) the } \\
\text { available scheduling software tools. Scheduler's informal } \\
\text { authority also plays an important role in the outcome of the } \\
\text { schedules. }\end{array}$ & $\begin{array}{l}\text { International Journal of } \\
\text { Production Economics }\end{array}$ \\
\hline 4. & $\begin{array}{l}\text { Burgess et al. } \\
(2007)\end{array}$ & $\begin{array}{l}\text { The paper examines the pervasiveness of } \\
\text { contemporary versus traditional types of } \\
\text { performance measurement system in an emerging } \\
\text { economy, and links incidence to key } \\
\text { organisational factors of size, age and ownership. }\end{array}$ & $\begin{array}{l}\text { Contemporary performance measurement systems are } \\
\text { found to be more prevalent than the traditional ones. The } \\
\text { type of PMS is significantly associated with size and } \\
\text { ownership. Large (number of employees) and foreign- } \\
\text { owned companies tend to use contemporary PMS. }\end{array}$ & $\begin{array}{l}\text { International Journal of } \\
\text { Productivity and } \\
\text { Performance } \\
\text { Management }\end{array}$ \\
\hline 5. & $\begin{array}{l}\text { Gunasekaran and } \\
\text { Kobu (2007) }\end{array}$ & $\begin{array}{l}\text { This is a literature review paper aiming to } \\
\text { determine the key performance measures and } \\
\text { metrics in supply chain and logistics operations. }\end{array}$ & $\begin{array}{l}\text { A list of key performance measures/metrics in logistics and } \\
\text { supply chain environment has been listed and grouped } \\
\text { according to the SCOR model of "Plan, Source, Make, } \\
\text { Deliver". }\end{array}$ & $\begin{array}{l}\text { International Journal of } \\
\text { Production Research }\end{array}$ \\
\hline 6. & Moullin (2007) & $\begin{array}{l}\text { This paper offers a number of definitions of } \\
\text { performance measurement. }\end{array}$ & $\begin{array}{l}\text { There is an apparent relationship between performance } \\
\text { measurement and organisational excellence. }\end{array}$ & $\begin{array}{l}\text { International Journal of } \\
\text { Health Care Quality } \\
\text { Assurance }\end{array}$ \\
\hline
\end{tabular}


7. Tang and Tomlin This paper presents a unified framework and five (2007)

8. Witcher and Chau (2007)

9. Hall (2008)

10. Bongsug (2009) This paper attempts to offer practical approaches to performance measurement and to present a list of essential Key Performance Indicators (KPI)

11. Chapman and This paper aims to analyse the complex Kihn (2009)

relationship between information system integration approaches, such as Enterprise Resource Planning systems and management control as a means to infer a link to business performance.

12. Verdecho et al. (2009)

The main aim of this paper is to analyse the performance measurement systems for interorganisational and collaborative environments by defining a typology comprising two dimensions: degree of relationships among collaboration elements and integration of collaboration within the PMS.

13. Akyuz and Erkan This paper aims to provide a critical literature
Flexibility has been highlighted as a powerful element to mitigate supply chain risks.

Strategic management of an organisation should consider the long-term and the short-term capabilities, which include core capabilities and core competences, crossfunctional management and top executive audits.

Work performance has a positive correlation with a comprehensive performance measurement system, which supports the argument that managerial work performance can be enhanced by comprehensive performance information.

In supply chain performance measurement, companies should focus on only a small number of KPI that are critical to their operations management, customer service and financial performance.

A management control is made up of the four design characteristics of the information system integration; each of which is related to both perceived system success and business unit performance.

Although performance measurement systems may support the management of collaboration relationships amongst companies, further understanding is needed to identify the elements and interactions among collaborative elements and how they can be integrated within a performance measurement system.

Performance measurement in supply chain is still an open research area. Further research needs to focus on empirical cross-industry research, framework development and application of performance measurement systems to modern supply chain.
International Journal of Production Economics

Management Decision

Accounting, Organization and Society

Supply Chain

Management: An

International Journal

Accounting, Organization and Society

Production Planning and Control

International Journal of

Production Research 
14. Grafton et al. The paper examines the processes through which (2010) the availability of broad-based strategic performance information impacts on the performance outcomes of organisations.

15. Manikas and Terry (2010)

16. Mundy (2010)

17. Veen-Dirks (2010)

18. Braz et al. (2011) The paper presents the results of an action research study carried out with the aim to improve the performance measurement systems within the maritime transportation of an energy company.

19. Gomes et al. (2011)

The paper examines the current views of manufacturing executives on key aspects of performance measures particularly on current practices related to extent of use, predictive value and availability of information for sixty three performance measures.

20. Najmi and Makui The paper proposes a conceptual model for (2012) measuring supply chain performance. The model can be used for most organisations with the same
In building organisational capabilities and performance, managers are encouraged to incorporate the multiple financial and non-financial performance indicators into the contemporary performance measurement systems, and it is imperative that performance evaluation schemes are also designed to reflect these measures.

The effective measurement and improvement of the operational performance (e.g. utilisation of storage space within cold rooms in the fresh produce supply chain) can lead to the achievement of higher levels of service at substantially reduced costs.

The capability of organisations to balance different uses of management control systems is affected by a number of factors: internal consistency, logical progression, historica tendency, dominance and suppression.

The survey data indicated consistent evidence that the importance attached to performance measures is different for the two uses. Companies place more importance to both financial and non-financial performance measures for the periodic evaluation than for rewards purposes.

Reviewing a company's performance measurement system is challenging. This is typically due to the degree of involvement of the users, the assessment of performance measures, the establishment of targets, and data availability.

Manufacturing organisations need to re-orientate their performance management cultures and emphasise softer performance-related measures, in particular the social responsibility.

A conceptual model for measuring supply chain performance has been developed according to performance metrics interdependencies. The model links the strategy to
Accounting, Organization and Society

British Food Journal

Accounting Organization and Society

Accounting, Organization and Society

International Journal of Production Economics

International Journal of Operations \& Production Management

Production Planning \& Control: The Management of 
class of industry sector.

21. Pavlov and Bourne (2011)

22. Danese and Romano (2012)

23. Franco-Santos et al. (2012)

24. de Lima et al. (2013)

25. Taylor and Taylor (2014)

26. Taticchi et al. (2014)

27. Koufteros et al. (2014) consequences. Delphi study. implementation. literature review.
The paper aims to address the problems within the existing research to evaluate the effects of performance measurement on performance.

The paper analyses the impact of downstream integration on supply network efficiency and the moderating effect on this relationship of supply network performance measurement systems.

The paper presents a conceptual framework for understanding the literature on the consequences of contemporary performance measurement systems and the theories that explain these

The paper aims to better understand the roles of performance measurement systems via a review of operations management literature and the

The paper presents a study of performance measurement systems (PMS) and the organisational factors which might have an influence on the effectiveness of PMS

This paper reviews the existing literature related to decision-support tools and performance measurement for sustainable supply chain management via the narrative and systematic

The paper reports a study to provide explanation of the effect of performance measurement systems on organisational capabilities and the performance measures.

Performance measurement exhibits three distinct effects on the organisational processes that deliver performance: the trigger, guidance and intensification effects. These have been demonstrated by a theoretical model.

There are moderating effects from the relationship between downstream integration and supply network efficiency to supply chain performance measurement systems. In order to strengthen the impact of downstream integration on supply network efficiency, managers should combine interventions on downstream integration and supply network performance measurement systems, rather than investing and focusing on downstream integration only.

Contemporary performance measurement systems significantly affect people's behaviour, organisational capabilities, and performance. This is, however, directly related to the way the measurement system is designed and used and how well it fits the context of operations.

Continuous improvement, organisational learning and change management are new elements that characterise the roles of the performance measurement system within the context of operational strategy.

Theoretically, the paper examined some of the antecedents to the effective implementation of a performance

measurement system. Practically, it provides practitioners with an understanding of the factors that can influence the effectiveness of their PMS implementation.

The review found the evidence of a growing research field the need for integrated performance frameworks with new generation decision-support tools that incorporate triple bottom line (TBL) approach for managing sustainable supply chains.

A comprehensive nomological network relating types of performance measurement systems' uses to organisational capabilities and performance. PMS lead to improved
Operations

International Journal of Operations \& Production Management

International Journal of Production Research

Management Accounting Research

International Journal of Production Economics

International Journal of Production Research

International Journal of Production Research

Journal of Operations Management 
capabilities and impact performance; 'Diagnostic Use',

amongst others, is the most constructive explanatory

variable for capabilities.

According to Fiat's WCM, the performance measurement system is based on a complex and formal

International Journal of

Production Research
Vagnoni (2015)

The paper presents the theoretical elements that

underpin the model of the Fiat world class

manufacturing (WCM) as an alternative to lean

production from the point of view of Strategic

Management, Management Accounting,

Operations Management and Performance

Measurement. auditing/benchmarking process, and fosters day-to-day

management operations. 


\subsection{Findings}

The review generated five key findings related to the research questions. The following sections discuss each of them by avoiding addressing individual PMS unless there are contradictory findings.

\subsubsection{Typical use and characteristics of PMS}

PMS are generally used in five different dimensions within all areas of the organisation:

- Measuring performance. Hall (2008) and Pavlov and Bourne (2011) clearly asserted that if things cannot be measured, then they cannot be improved.

- Strategy management. Performance measurement enables implementations of strategy and focus on strategic goals (Akyuz and Erkan, 2010; Grafton et al., 2010; Franco-Santos et al., 2012).

- Communication (Akyuz and Erkan, 2010; Franco-Santos et al., 2012).

- Influencing behaviour (Hall, 2008; Veen-Dirks et al., 2010; Danese and Romano, 2012)

- Learning and improvement, by testing, reviewing, revising and refining (Gunasekaran and Kobu, 2007; Akyuz and Erkan, 2010; Mundy, 2010; Braz et al., 2011; de Lima et al. 2013).

It has also been suggested that PMS may also be used for continuous improvement, change management (de Lima et al. 2013), diagnostic control mechanisms and interactive purposes (Akyuz and Erkan, 2010; Mundy, 2010; Franco-Santos et al., 2012; Koufteros et al., 2014).

By narrowing the scope, Gunasekaran and Kobu (2007) and Bongsug (2009) studied the roles of performance measurement in the supply chain and concluded that they are fundamental. Particular attention was granted to the following potential uses:

- Determining success factors,

- Meeting customer needs,

- Better comprehend processes,

- Enable communication and collaboration,

- Detect opportunities for improvement, by providing feedback,

- Decision-making based on priorities and facts, 
- Track and enable progress.

Taticchi et al. (2014) presented evidence of the growing research field in sustainable supply chain, and argued the needs for an integrated performance framework to manage sustainable supply chain. PMS can support supply chain partners to reduce risks and adapt to market dynamics with greater ease. This reduces the impact to the supply chain due to short-term changes in demand (Tang and Tomlin, 2008). They can also be applied as a feedback system enabling organisations to learn about the level of its performance and trigger changes (Pavlov and Bourne, 2011).

Even though performance measurement is directly linked to efficacious supply chain management, organisations often question how to make a performance measurement work in practice, in particular in operations and production planning (Bongsug, 2009). Franco-Santos et al. (2012) highlight how significant it is for managers and employees to respond to PMS in order to achieve success. Investigation also suggests that PMS are not sufficiently integrated into daily activities so as to manage performance collaboratively throughout all levels of the organisation (Verdecho et al., 2009).

The ideal PMS (Gunasekaran and Kobu, 2007; Akyuz and Erkan, 2010; Gomes et al., 2011; Pavlov and Bourne, 2011) should:

- Combine organisational effectiveness goals with operational efficiency,

- Encompass a proactive and continuous approach,

- Be simple and easy to implement and use,

- Be inclusive of both financial and non-financial measures,

- Suit all levels of the supply chain,

- Be tailored to each area of the supply chain,

- Take experience into consideration,

- Provide ex-ante information as well as feedback, and

- Be valid and reliable.

However, establishing and implementing such systems require taking large number of variables into consideration simultaneously. Thus suggested future research focuses especially on the development of a framework that allows for partnership, collaboration, and flexibility, whilst taking into consideration information technology, business processes and 
the roles and responsibilities of individuals carrying out the processes (Bongsug, 2009; Akyuz and Erkan, 2010; Najmi and Makui, 2012).

Finding 1: Current uses and characteristics of PMS are somewhat different to those suggested by the aforementioned researchers. There is scope to use PMS as exante tools to improve efficiency and achievement of organisational goals.

\subsubsection{PMS users}

The literature abounds with evidence that management are the prime users of PMS (Shepherd and Günter, 2006; Hall, 2008; Veen-Dirks et al., 2010; Braz et al., 2011; Danese and Romano, 2012) and some antecedents to the effective implementation of a PMS (Taylor and Taylor (2014). The use of both financial and non-financial PMS is paramount to the business success (Franco-Santos et al., 2012). Although managing practices affect operational performance (Pavlov and Bourne, 2011), it is executive, supervisory and operative managers who are periodically reviewed using PMS. Therefore, to ensure the use of financial and nonfinancial PMS, performance evaluation schemes have to reflect these measures and provide feedback (Hall, 2008; Grafton et al., 2010).

It has also been suggested that PMS not only evaluate performance but also guide future development and provide direction to the entire supply chain (Zhaofang et al, 2006). As a result, in recent years, organisations have chased the goal of developing PMS that support managers and employees alike (Hall, 2008), whilst ensuring that the metrics are balanced and aligned at a strategic, tactical and operational level (Najmi and Makui, 2012). More benefits may be achieved if the relationship amongst all levels is deeper (Verdecho et al., 2009).

Pavlov and Bourne (2011) suggest PMS should also be employed by all levels of the organisation to provide guidance and subsequently to improve results, through the use of PMS as ex-ante tools to influence action.

Finding 2: PMS have been mostly applied at strategic and tactical levels. Nonetheless, there is space for their applications at an operational level. By providing all individuals within a supply chain with accurate and timely information beforehand, PMS can provide an effective, ex-ante guidance. 


\subsubsection{Influence of PMS on behaviour and performance}

Research demonstrates that measuring supply chain performance provides a greater understanding of the supply chain, which positively stimulates managerial and employee behaviour and consequently improves performance (Shepherd and Günter, 2006). FrancoSantos et al. (2012) further pointed out that the extent to which PMS influence individuals is directly associated with the way the system is designed, developed, used and most importantly, the context in which it operates (Franco-Santos et al., 2012).

PMS can also help understand the effects that performance measures might have on an individual's behaviour within the supply chain. In light of this knowledge, continuously improving the measures will enable faster customer order fulfilment and greater efficiency than that of competitors (Manikas and Terry, 2010; Najmi and Makui, 2012).

Koufteros et al. (2014) presented some evidence to suggest that PMS may lead to improved capabilities which can impact performance. The diagnostic use of PMS allows line managers to monitor performance against a plan and then to identify corrective actions needed if the performance deviates from the plan.

When appropriate feedback mechanisms are in place, PMS can help managers improve their performance. Constructive feedback can influence performance by encouraging managers to translate a strategy into operational tasks. This, in turn, will automatically influence employees to successfully perform the tasks that will meet the strategic objectives. Thus, people's behaviour and performance are greatly influenced in a number of ways: motivation, cooperation, goal commitment, role understanding, self-monitoring, managerial decisionmaking, and relationship amongst departments (Pavlov and Bourne, 2011; Franco-Santos et al., 2012). However, this is only possible if roles and responsibilities are clearly defined and communicated (Bongsug, 2009).

Others argue that PMS are not expected to have a direct impact on behaviour but rather indirectly affect performance by clarifying expectations, increasing psychological empowerment and providing feedback to enhance intrinsic task motivation (Hall, 2008). Individuals require sufficient information to perform tasks effectively. A lack of information regarding job-related goals and the most effective job behaviours can result in efforts that are inefficient, misdirected or insufficient, and thus reduce job performance (Hall, 2008). 
To enhance the development of psychological empowerment, there is a need to provide adequate performance information. There are a number of theories from psychology suggesting that timely information about task behaviour and performance can improve psychological empowerment (Collins and Harris, 1992). Specifically, intrinsic task motivation is increased if individuals are provided with appropriate feedback about the results of operations. The greater the quality of the information provided, the greater the motivating potential (Ilgen et al., 1979). There is also an evidence to suggest that undertaking a task without sufficient knowledge of intended results is likely to frustrate and lead to the use of emotion rather than data, which subsequently leads to reduced motivation (Hall, 2008).

Tang and Tomlin (2008) further suggest that organisations can obtain a significant value in implementing the flexibility strategy to help diminish process risks linked to varying volumes. Kolehmainen (2010) suggests that this can be achieved by including flexibility measures in PMS. Supply chains are considered dynamic systems that have to continuously adapt to maintain competitive in the current environment, thus there is always a challenge to manage and improve supply chain (Najmi and Makui, 2012). A change in organisational culture is suggested to emphasise performance measures that result in short-term effectiveness and greater flexibility (Gomes et al., 2011).

Finding 3: Whether directly or indirectly, Performance Measurement Systems (PMS) impact behaviour and performance of individuals at all levels of the supply chain. How operational level employees are affected, however, depends on how managers translate strategic objectives into operational tasks.

\subsubsection{Linking PMS to decision-making}

PMS impact decision-making (Grafton et al., 2010; Franco-Santos et al., 2012) including the decisions that are non-financially related (Veen-Dirks et al., 2010). Experiential evidence gives particular importance to the environment of great uncertainty that involves decisionmaking tasks (Hall, 2008). This is also evident from a study by Taticchi et al. (2014) asserting that decision-making tasks should be combined with the integrated performance framework, particularly if the decisions involve triple bottom line (economical, environmental and social) sustainability performances.

PMS can be used for decision-making in two ways. The first is by higher-level managers to evaluate performance of lower managers and make decisions based on the outcome. The 
second possibility is to provide information beforehand, so as to support decision-making when resolving uncertainties. By innovating PMS, organisations can provide aligned metrics and can improve accuracy of data and flexibility in decision-making processes (Grafton et al., 2010; Braz et al., 2011; Pavlov and Bourne, 2011).

Environments that offer decision support may increase the performance of a supply chain by identifying areas for improvement (Angerhofer and Angelides, 2006). Individuals making decisions at different hierarchical levels may find this particularly useful (Braz et al., 2011). Nevertheless, caution is required as there is evidence to suggest that because making decisions is a cognitive process, they are not flawlessly rational. As such, individuals may evaluate and interpret data biased towards emotional preferences (Tayler, 2010). A gap has been identified regarding the application of PMS for decision-making and control at an operational level (Akyuz and Erkan, 2010).

Finding 4: PMS can influence decision-making in two ways. The first is to support decisionmaking based on feedback using the performance measurement data. The second is still theoretical and considers the provision of information before actual occurrences (ex-ante) in order to guide decisions towards the outcomes that will most benefit the performance measurement and in turn the organisational goals.

\subsubsection{Information Technology and PMS}

Chiarini and Vagnoni (2015) presented the theoretical elements underpinning contemporary PMS largely based on a complex and formal auditing and benchmarking processes fostering day-to-day management operations including supply chain. In this respect, technology was identified to be fundamental in the success of a supply chain as they are essential in the implementation of the PMS (Braz et al., 2011; Gomes et al., 2011). Information Systems are often used as an approach to manage business performance within segmented areas of the trade. It allows for the information flow to be accessible, accurate and timely, enabling individuals in the supply chain (Angerhofer, Angelides, 2006; Hall, 2008).

Organisations tend to assume that there is a strong relationship between information systems and the success of an organisation (Chapman and Kihn, 2009). Hefty investments are being placed in the development and implementation of decision support systems that sustain PMS (Neely et al., 2005). Organisations are often willing to invest in complex projects that involve information system integration approaches, including Enterprise Resource Planning systems 
(Chapman and Kihn, 2009). Decision support systems are typically interactive computerised systems that provide data, documents, knowledge, and models to solve problems and make decisions. Whereas some systems are directed at managers, others help all employees across the supply chain. They are designed to ease decision-making and allow for quick response to continual changing demand, but have been known to demotivate and restrict decision-making (Bongsug, 2009; Schuff et al., 2010).

Technology can be as much of a facilitator as it can be a barrier (Verdecho et al., 2009). According to Braz et al. (2011), information systems are often conceived with such high complexity that they are either unserviceable or fail due to lack of buy-in. Companies should consider the organisations' culture and how to use information systems to overcome the degree of high environmental uncertainty, what traits of performance they are trying to improve and how to measure them, even before committing to such large investments in resources (Najmi and Makui, 2012; Franco-Santos et al., 2012). Limited research has been carried out in exploring the financial and time-related costs of implementing and continuously updating performance measurement information systems (Shepherd and Günter, 2006; Braz et al., 2011). Nevertheless, this is also a fact to consider.

It has also been discussed that information systems may not always be as effective management tools as perceived. However, they have the potential to improve employees working practices as a guide and learning mechanism rather than providing them with answers (Wouters and Wilderom, 2008). There is evidence to suggest that information systems provide flexibility, although there has also been the case that they have too many controls preventing individuals from making decisions (Chapman and Kihn, 2009; Grafton et al., 2010). By considering empowerment, supplier relationship and cross-training, organisations tend to become more flexible (Tang and Tomlin, 2008). Thus, information systems should be conceived to guide individuals allowing for dynamic environments (Shepherd and Günter, 2006).

Finding 5: Information systems are fundamental in a supply chain as they provide accessible, accurate and timely information. However, if they are too complex or there is no buy-in, they become a barrier.

\subsection{Identification of gaps}

In the context of supply chain operations, Performance Measurement Systems (PMS) are widely used for strategic and tactical analysis of organisational performance, but have not 
been widely applied at an operational level. This is also acknowledged by Gunasekaran et al. (2001) who claimed that the performance measures are generally imbalance across the three levels of organisational hierarchy: strategic, tactical and operational, and that the distinction between metrics at those levels is often lacking. Provided PMS are aligned from a strategic to an operational level, there is strong evidence to suggest that should PMS be applied as exante support systems, individuals at all levels of an organisation could benefit from PMS to guide them in their decisions. There is also potential for the use of Information Technology as enablers of accurate and timely data related to performance measurement. Nevertheless, a framework that provides performance measurement support and information to drive performance throughout the various levels of the supply chain appears to be lacking.

\section{METHODOLOGY}

The goal of the project described in this paper is to improve the ability of an organisation's supply chain to adapt to changing customer demand using a performance measurement by improving the decision-making process at an operational level.

Based on the gaps defined in the literature review, the objectives were then set to:

1. Determine how to facilitate decision-making in order to increase flexibility in adapting production to customer demand.

2. Analyse and reduce performance measurement misalignment throughout the supply chain.

3. Understand how, within the supply chain operations, performance measurement can support decision-making.

4. Apply the knowledge captured and develop a framework that allows individuals to use performance measurement as support systems, driving ex-ante informed decision-making at an operational level within the supply chain.

A research methodology has been adopted to include three stages. Initially, the data were collected and subsequently analysed. In the second phase, a framework, composed of a set of models, tools and a processes, was developed and continuously improved using the PDCA approach (Deming cycle). Finally, the applicability of the framework was tested at a major, global brand beverage company to confirm its practical applicability. Several tools were employed throughout the three stages. These included semi-structured interviews, questionnaires and probing. 


\section{DATA COLLECTION AND ANALYSIS}

The wide variety of products and high capacity production at the case company made it an ideal avenue for this study. Demand is customer-driven originating at the point of sales or supermarket chains and communicated on a weekly basis to the production sites by the head office (Figure 1). The fluctuating demand in products has resulted in a need to develop flexibility mechanisms (including lean tools), in order to rapidly respond and maintain a competitive edge.

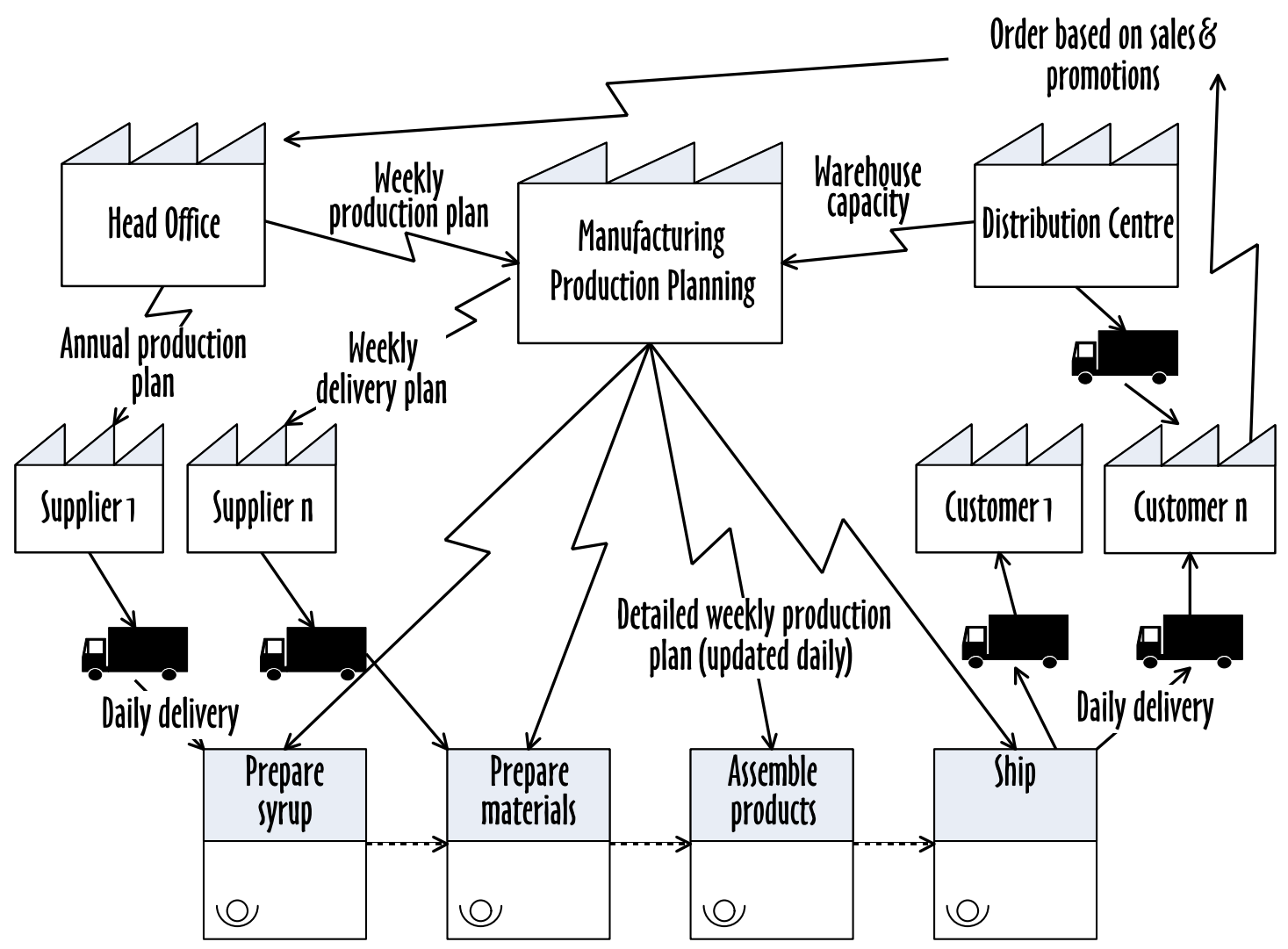

Figure 1: Value Stream Map of the case company’s supply chain

In order to identify the strengths of PMS and to extract concrete examples of the issues that exist at the supply chain of the case company, and thus to achieve greater efficacy in the decision-making, five middle and top managers who have a combined experience of 107 years mainly in food industries were interviewed using the semi-structured interview technique.

Each interview lasted between 60 and 120 minutes, covering the following themes: the details of the supply chain, perceived triggers, influencing factors, root causes, standard 
operating procedures, the performance measurement in place, the importance and impact of decision-making across the supply chain, and the relevance of developing a structured approach at an operational level. The interviews were manually documented and a sound basis for understanding the main barriers was established. The findings obtained from these examples were then used to develop various models and the process framework, with direct applicability to the operational level.

To further understand the alignments between the performance measurement and the operational issues, a questionnaire was sent to 30 individuals ranging from shop floor technicians and office workers, to middle and top managers. The questionnaire was devised with the support of high-level managers to identify the key performance measures applicable to the supply chain. A six point Likert scale was applied; 1 being the most important and 6 being the least. The reasoning behind the answers provided was captured and then manually recorded. The questionnaire is shown in Figure 2.

\begin{tabular}{|c|c|c|c|}
\hline \multirow{2}{*}{ In your view, in what order woul } & \multirow[b]{2}{*}{$1=$ most important } & \multirow{2}{*}{\multicolumn{2}{|c|}{$6=$ least important }} \\
\hline & & & \\
\hline Factors & Production plan & Your department & The site \\
\hline Lowest cost & & & \\
\hline Utilisation & & & \\
\hline Yield & & & \\
\hline Water, CO2 emission, electricity & & & \\
\hline Adherence in cases & & & \\
\hline Output (every case counts) & & & \\
\hline
\end{tabular}

Figure 2: Questionnaire items

The results obtained from the data collected indicated that depending on the hierarchical level and role within the organisation, employees had different views as to the performance measures' priorities and the general organisational alignment. The six top and middle management levels indicated that the performance measures were all of high importance as they were all present in their pre-established yearly targets. Results also indicated that they perceived performance measures to be aligned throughout the site, which was further supported by their reasoning. In contrast, at a non-management level, the priorities of the performance measures varied depending on the department. 
Following the interview and questionnaire, a detailed investigation was carried out at the Planning Department. Roles and responsibilities, information systems, activities and respective processes, and other resources available were all considered. This was achieved by following employees' actions, analysing existing company documentation, in addition to interviews and workshops. Once a general understanding of the Planning Department was obtained, the decision-making process of a production change request was then documented. Subsequently gaps in the process were identified and a brainstorming session was carried out to understand how to fill the gaps.

As there were no clear performance measures for the Planning Department, a set of inherent measures was recorded and, with the support of the current and previous managers responsible for the department, a selection of the most significant was obtained. This information, alongside the decision-making evidence, was used to add and extract details from the framework. It also formed the basis for the development of the tools which allow for prioritising and displaying data. The main gaps were found to be the lack of use of data and clear targets when making decisions. In addition, an established procedure for decisionmaking did not exist and this opened up an opportunity for the development of the framework.

\section{FRAMEWORK DEVELOPMENT}

The outcomes from the preliminary research through interview, questionnaire and probing became the foundations of the proposed framework developed in several iterations with inputs from both theory and practice. In contrast with the existing performance measurement systems, the proposed framework takes the first step towards using performance measures as drivers. In addition, the framework integrates an illustration of how performance measures can be aligned throughout the supply chain, whilst incorporating the use of existing strategic level PMS. The business scorecard is given as an example.

The conceptual model has been developed with reference to a guiding equation shown in Figure 3 , in addition to the strategic and tactical factors that exist at the case company.

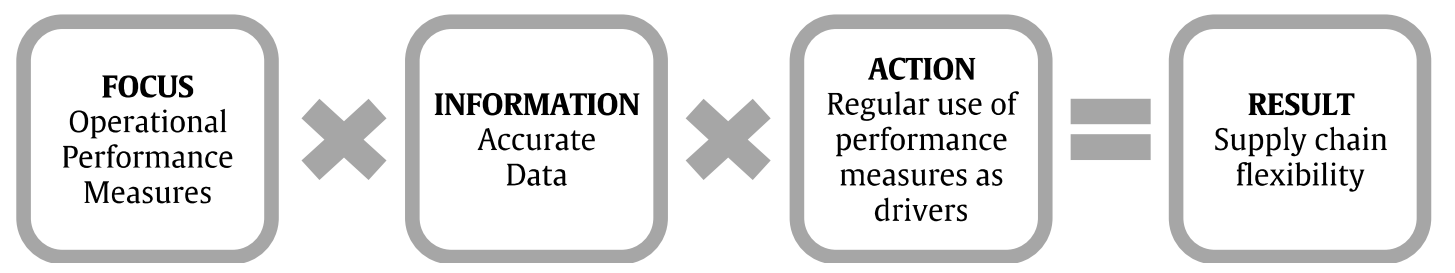


Figure 3: Graphical representation of the model equation

The model is strengthened with a process framework and a set of tools that aim to provide a graphical representation of how flexibility at an operational level can be achieved in practice. Decision-making at an operational level is triggered by two main sources: manufacturing performance and customer requirements. In both cases, the optimum decision is the one that creates the lowest impact and highest throughput to the supply chain. However, decisions are commonly made in an ad-hoc manner based on personal experience. The risk here is that individuals use common sense rather than information (Gunasekaran and Kobu, 2007).

The use of performance measurement in decision-making is therefore twofold: it drives the supply chain towards common accepted goals, and it provides the data to make informed decisions. As can be seen in the cone-like models (Figures 4 and 5), the framework proposes an organisational structure of a supply chain model and suggests how to align the performance measurement in order to achieve common goals.

Figure 4 and 5 to some extent exhibit similarities to the Information Technology (IT) framework of Laudon and Laudon (2014). However, the two frameworks serve different purposes. Our framework emphasises the fact that there is a need to communicate more effectively (across different levels of organisational hierarchy) so that the performance measures at a higher level can be deployed to the lower, operational levels (see Figure 5). 


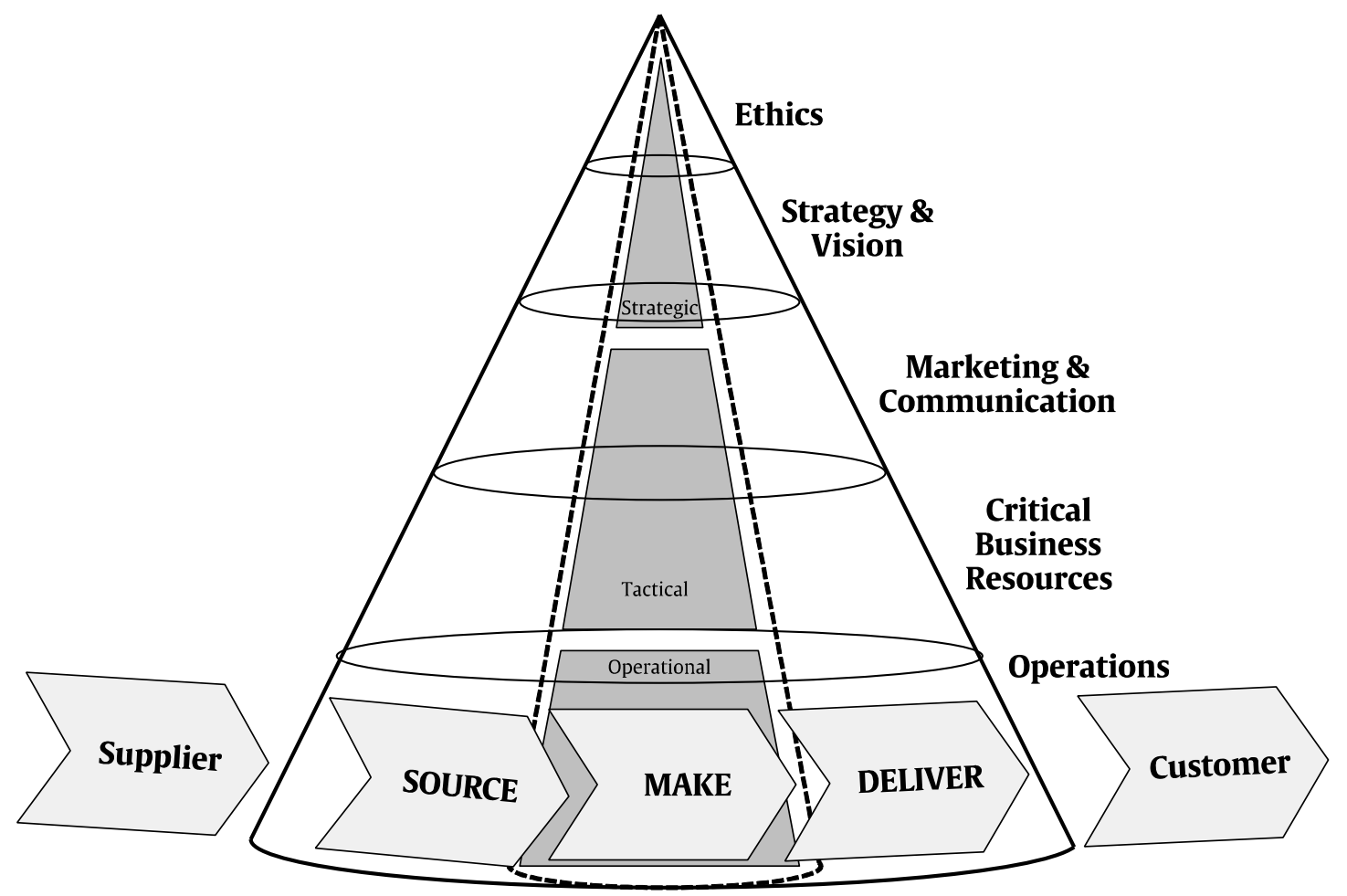

Figure 4: Linking supply chain model and various levels of decision

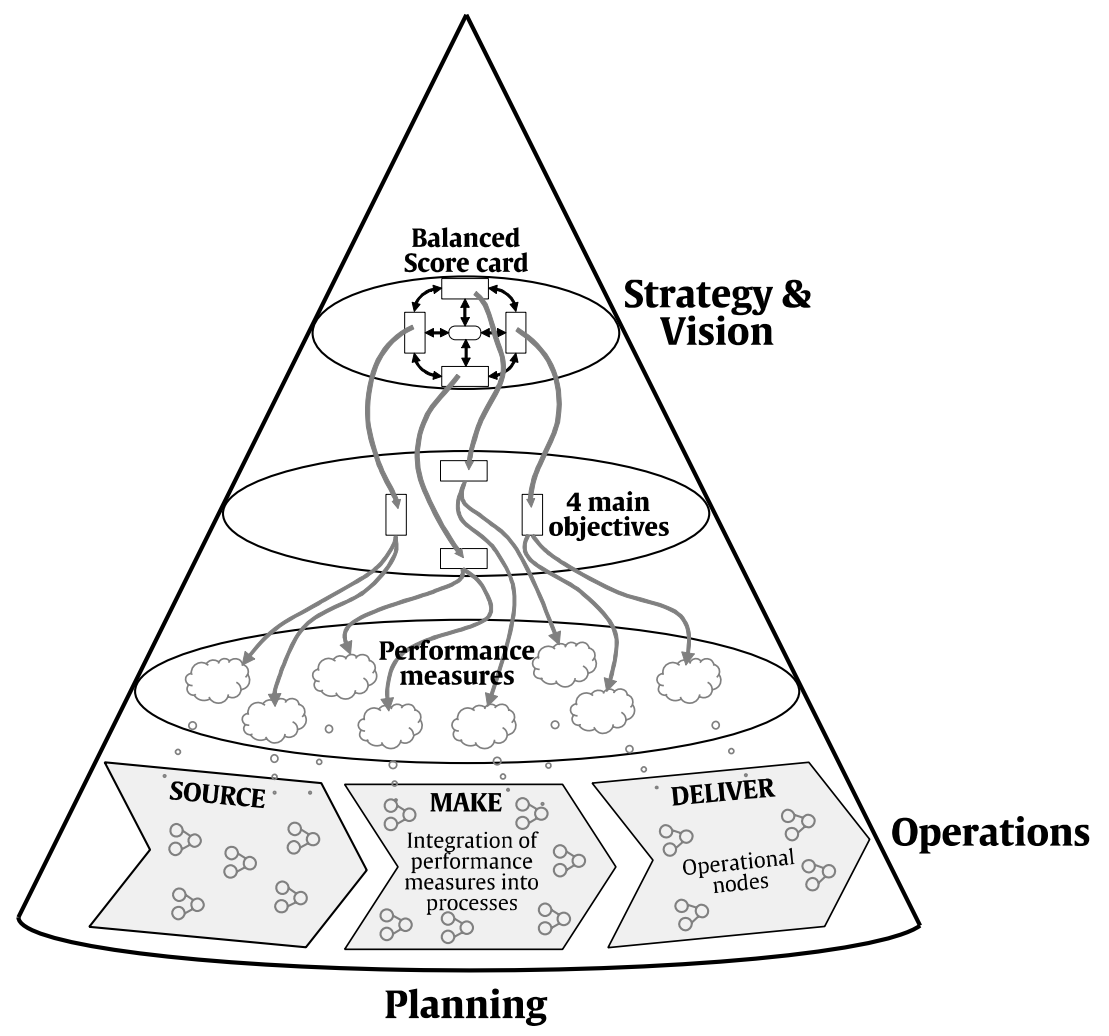

Figure 5: The alignment across the organisation 
To link the aligned performance measures with the decision-making process, a model illustrating the key elements involved in the process is shown in Figure 6 detailing where the process stands within the supply chain areas. Operational nodes form the components required to carry out an activity, including the decision-making in supply chain operations. Each area of the supply chain fulfils a series of repeated activities that can be summarised into a cluster of operational nodes. The decision-making process is illustrated in the form of a process framework (Figure 7).

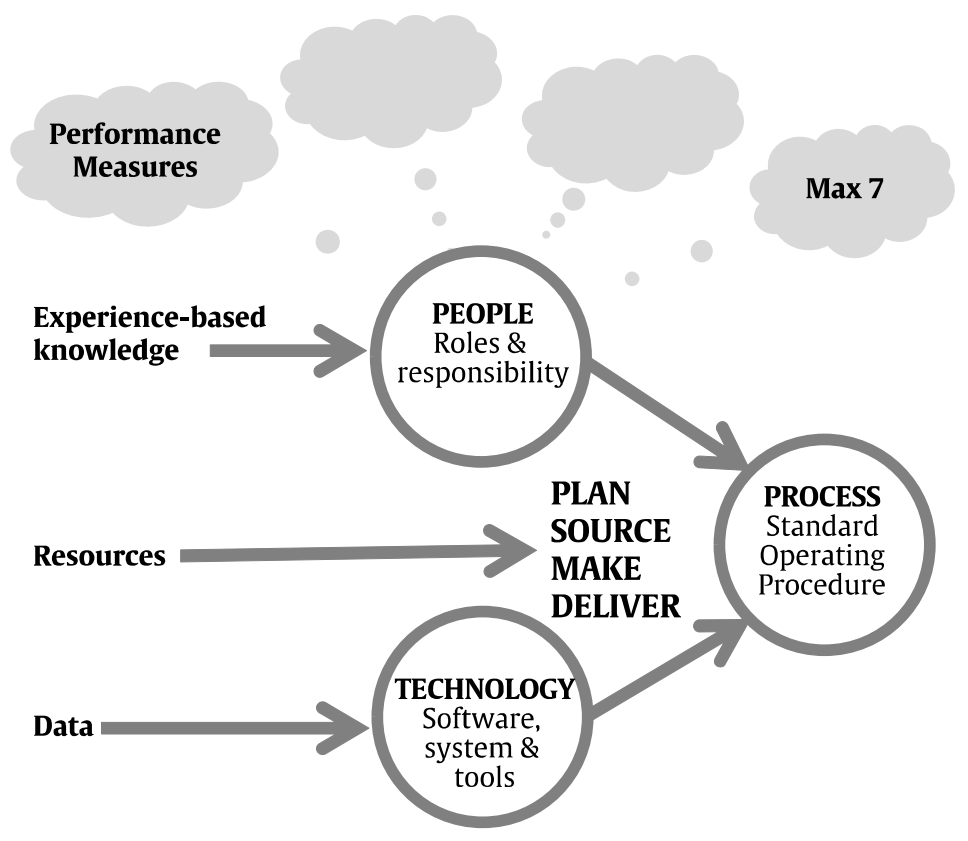

Figure 6: The operational nodes 


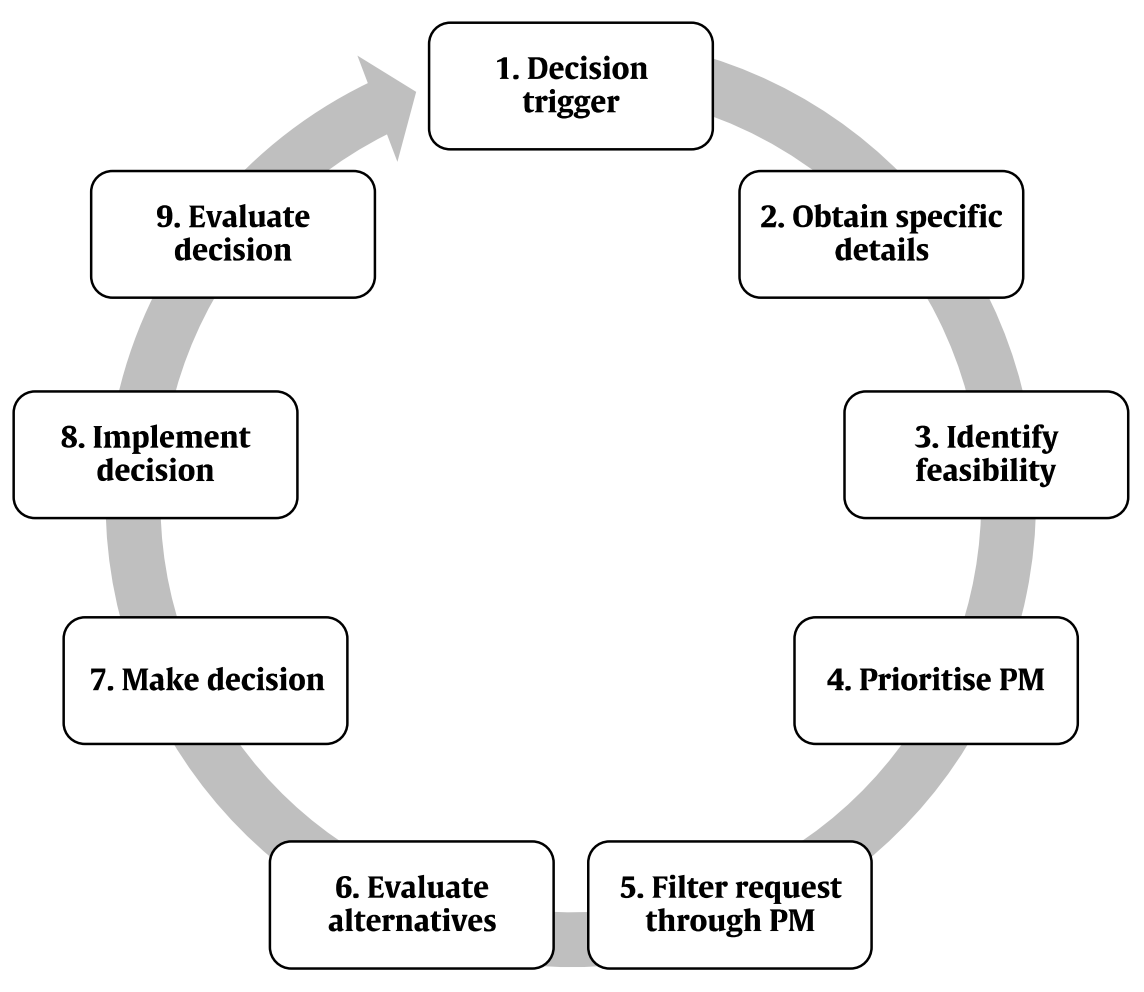

Figure 7: Decision-making process framework

\section{TESTING OF THE FRAMEWORK}

In order to demonstrate how the decision-making process and the supporting tools can be applied in a practical context, the proposed framework has been tested using three case examples which originated from the Planning Department, and thus the PMS alignment is identical in all cases. The main scorecard objectives (strategic level) were linked to the related PMS (operational level) as illustrated in Figure 5. Due to confidentiality, details have purposely been omitted. The PMS were then integrated into the production change decisionmaking process illustrated in the operational node model (Figure 8) and production change requests were subsequently applied. 


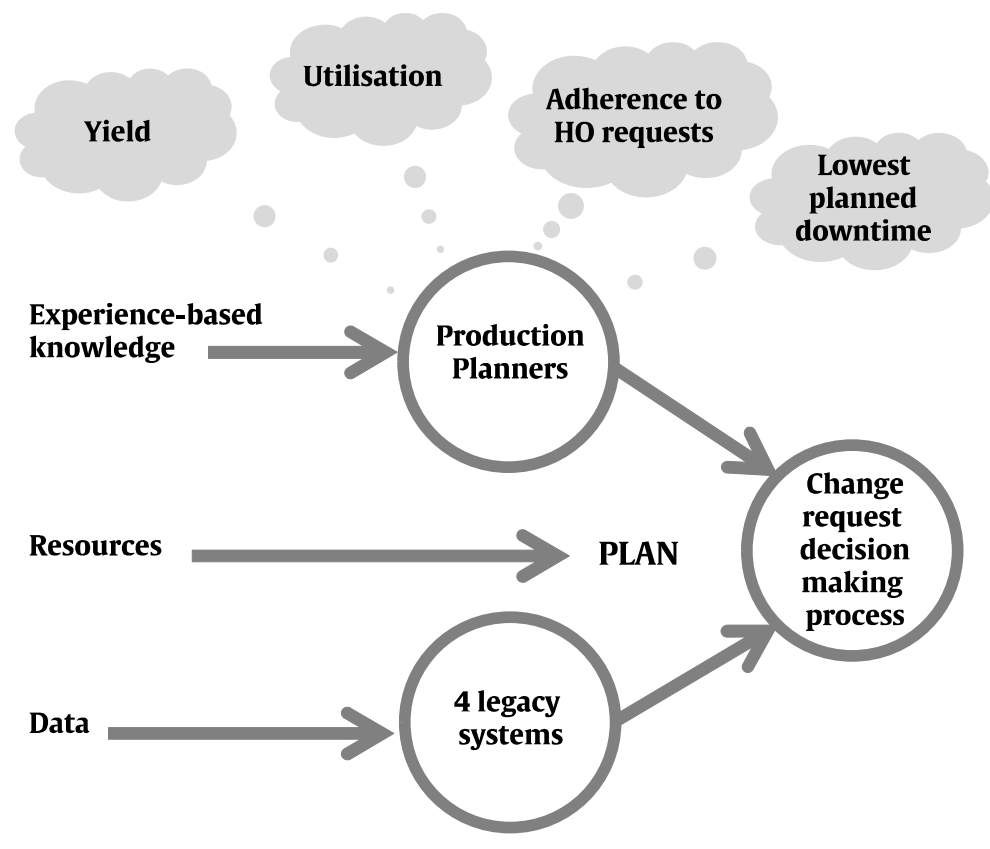

Figure 8: Operational nodes applied to the case study company

Prioritising the performance measures (step 4 in Figure 7) through pairwise comparison ranking, allows the users to perceive the importance of each criterion when making a decision. The pairwise comparison used here is akin to the one used in the Analytic Hierarchy Process (AHP) (Saaty, 1990). In AHP, the combination of the criteria makes up the goal of the comparison. Each criterion can further be decomposed into sub-criteria, and pairwise comparison and ranking may be done at this level taking into account the degree of importance for each comparison pair.

The two criteria (e.g. Yield vs Utilisation) are compared and the user decides which one is more important. The criterion with the most points was the preferred one, the remaining follows in order of the acquired points. It is not to make the decision for them, as it could limit individual's thinking, which has been evident to be prejudicial in terms of performance. As the case study examples are from the same time period the priorities of the performance measures are identical (Figure 9). 


\begin{tabular}{|l|l|l|l|l|l|l|l|}
\cline { 2 - 5 } \multicolumn{1}{l|}{} & Yield & Utilisation & $\begin{array}{l}\text { Adherence } \\
\text { to HO } \\
\text { request }\end{array}$ & $\begin{array}{l}\text { Lowest } \\
\text { planned } \\
\text { downtime }\end{array}$ & Total & \multirow{2}{*}{ Priority } \\
\hline Yield & & Utilisation & $\begin{array}{l}\text { Adherence } \\
\text { to HO } \\
\text { requests }\end{array}$ & Yield & Yield & $\mathbf{1}$ & Utilisation \\
\hline Utilisation & & Utilisation & Utilisation & Utilisation & 3 & $\begin{array}{l}\text { Adherence to } \\
\text { HO requests }\end{array}$ \\
\hline $\begin{array}{l}\text { Adherence to } \\
\text { HO requests }\end{array}$ & & & $\begin{array}{l}\text { Adherence } \\
\text { to HO } \\
\text { requests }\end{array}$ & $\begin{array}{l}\text { Adherence to } \\
\text { HO requests }\end{array}$ & $\mathbf{2}$ & Yield \\
\hline $\begin{array}{l}\text { Lowest } \\
\text { planned } \\
\text { downtime }\end{array}$ & & & $\begin{array}{l}\text { Lowest } \\
\text { planned } \\
\text { downtime }\end{array}$ & $\mathbf{0}$ & $\begin{array}{l}\text { Lowest } \\
\text { planned } \\
\text { downtime }\end{array}$ \\
\hline
\end{tabular}

Figure 9: Pairwise ranking comparison tool applied to case example

Naturally, the outcomes of the comparison could have been slightly different if the decision was made by different users. As the test aimed to demonstrate to the users how the proposed decision-making process and the supporting tools can be applied in a practical context, walkthrough tests were carried out together with the interview subjects and the results demonstrated the practicability of the theoretical framework.

Case A has been triggered by head office that urgently needs a specific product, and is a prime example of how using this framework reduces the time taken to make an informed decision. Case B originated from within the site due to a manufacturing line maintenance requirement and exemplifies how accurate data allow for treating uncertainty and making a decision based on actual impact rather than perception. The last example, Case $\mathrm{C}$, is internally driven and shows how the unavailability of the data required at the right time may lead to a decision that is less beneficial towards meeting the organisational goals. These examples are further discussed in the following sub-sections.

\subsection{Case A - Shortening lead time}

Around 72 hours prior to producing a certain flavour of beverage, the production planning team received a telephone call from head office requesting for the product to be produced within the next 48 hours. The justification was merely due to the customer demand. Within the next two hours the decision as to whether to accept or decline the request was debated amongst the head office, production planning and production managers. The lengthy decision was in fact a consequence of gathering information from numerous sources, which in the end suggested that the request was accepted. By following the decision-making process developed in this research project, it was possible to evaluate the consequences of the 
changes and make the same decision within 30 minutes. Figures 10 and 11 show the performance measurement outputs from Case A.

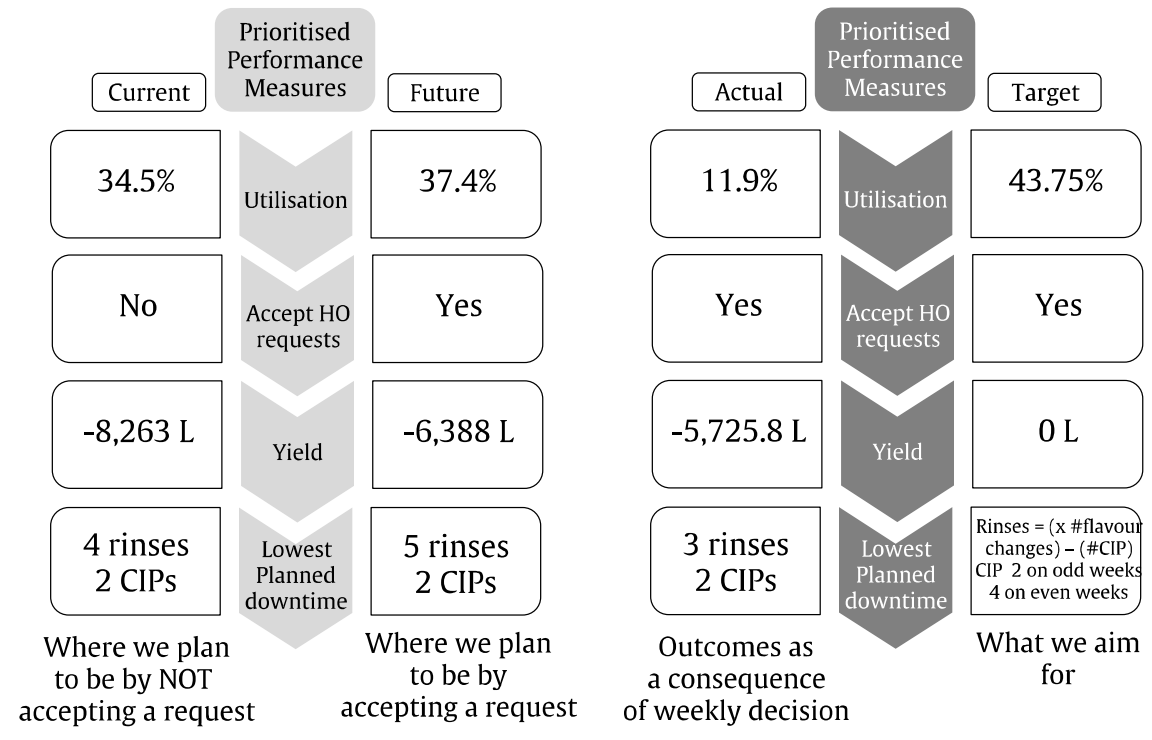

Figure 10: Performance Measurement data output from Case A

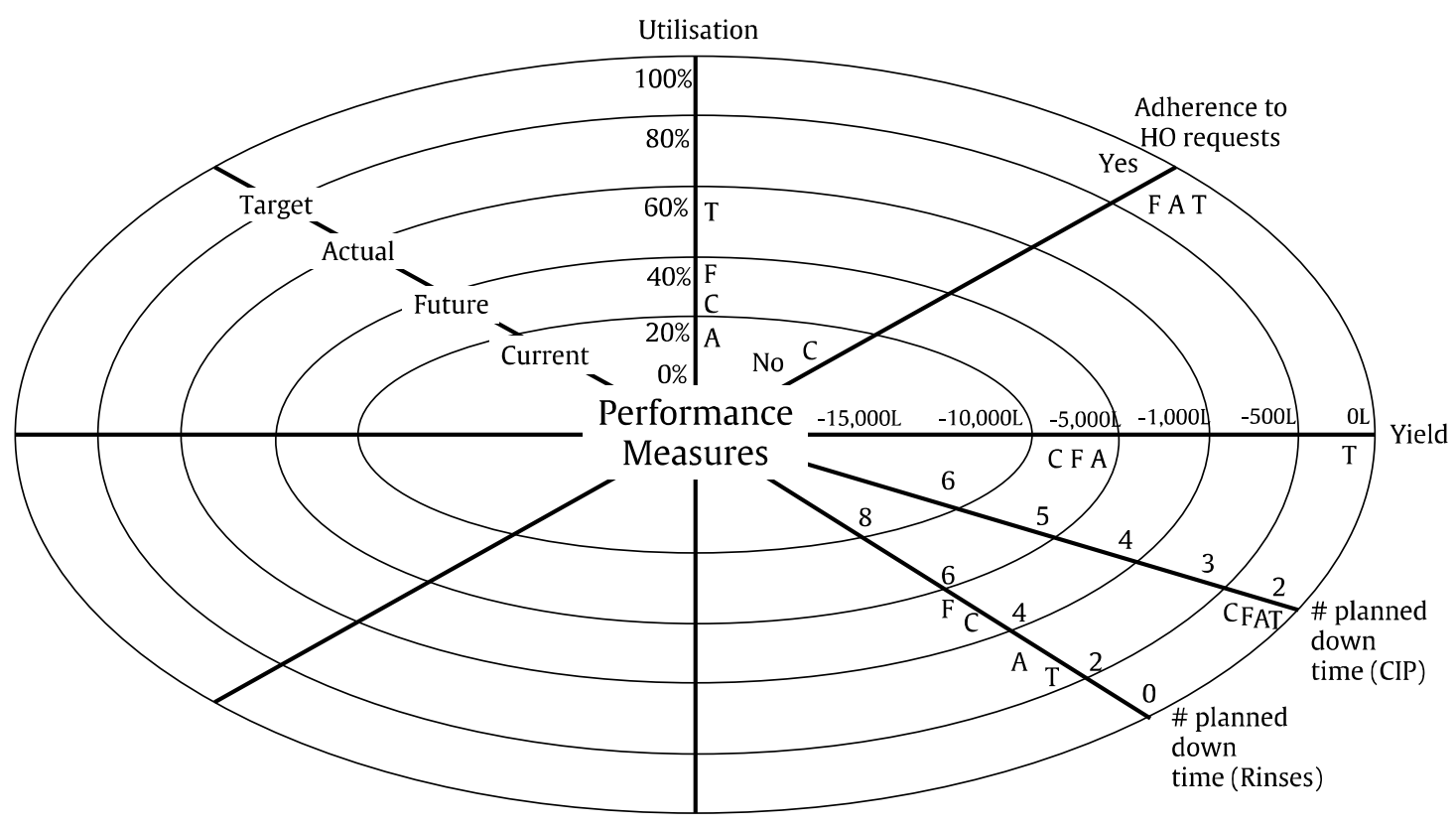

Figure 11: Spider-web chart of performance measure output from Case A

\subsection{Case B - Unscheduled maintenance}

With a five day notice, the production managers identified that the manufacturing line producing PET bottles required work that interrupted production. This was communicated to 
production planning in order to make the decision as to if and when this could occur. To accommodate this request, using expert judgment and liaising with the head office, the planning team decided to remove Beverage A and Beverage B in the pack size with the least demand. When asked about the impact this would cause on overall production, qualitative answers were provided.

In contrast, based on the data from the production plan and the quantity of product removed, the impact this decision would cause on the performance measure targets can be calculated (quantified). The data indicated that there would be a reduction of $2.4 \%$ in utilisation. However the number of rinses (non-productive time) would decrease by two and the yield would upsurge by decreasing the loss of final product by $7 \%$ of a batch. In terms of the company objectives, this meant that the cost of stopping the line (not including maintenance costs) was somewhat compensated by savings in other areas. Even though the production planning team does not deal with costs, the PMS reflect the strategic goals, which are strongly related to costs.

The decision-making process applied in this case has allowed effective and efficient analysis, whereas the production planners usually applied ad-hoc reasoning to make the decision. Had they applied the proposed decision-making, they could have simulated various options to identify the one with less impact to the organisation. Figures 12 and 13 show the performance measurement outputs from Case B.

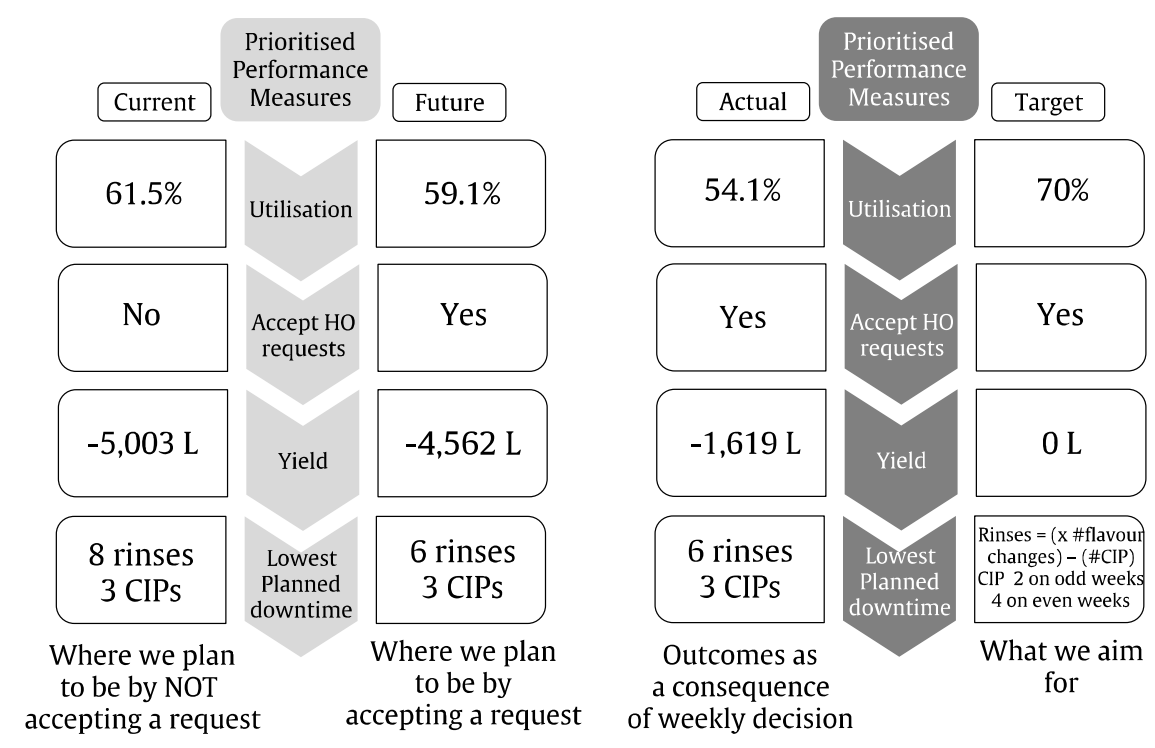

Figure 12: Performance Measurement data output from Case B 


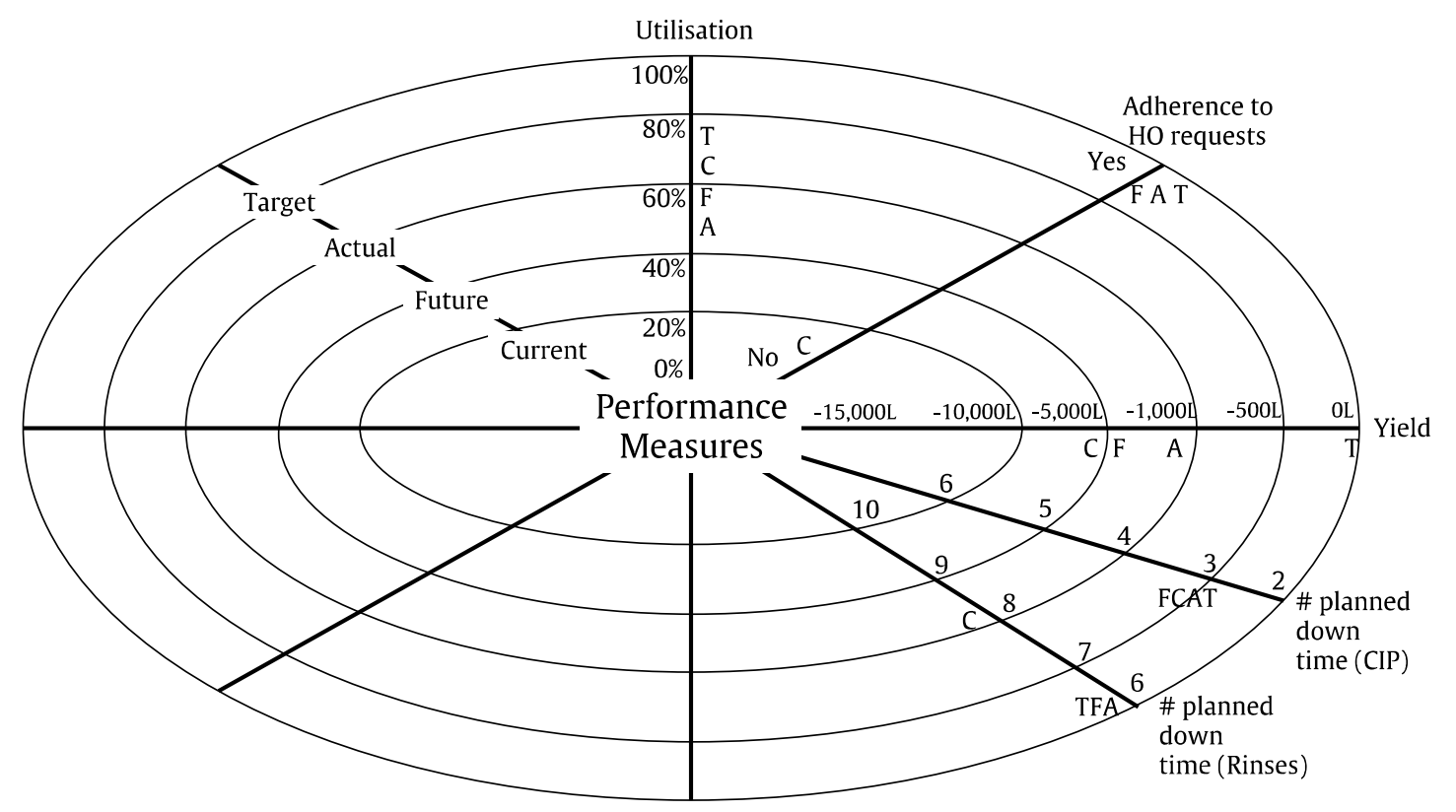

Figure 13: Spider-web chart of performance measure output from Case B

\subsection{Case C - Reducing throughputs}

An issue in producing a sample product on a production line had been raised by a production manager at a weekly production plan meeting. The planning team communicated this to the head office and a decision to cut the product from production was made 48 hours prior to the scheduled production time. The production planner who liaised with the production manager and the head office made the decision based on expert judgment and consensus.

Once again, the decision-making process framework was applied and the performance related quantitative data were used to conclude that the most beneficial decision for the organisation would have been to maintain the plan, rather than to cut production. By making this decision, utilisation was decreased by $5 \%$ and the head office request was, in the end, not fulfilled. In addition, the number of rinses was maintained as the product sample was the same flavour as the predecessor and successor. The yield was unaltered. Even though producing a sample product would have required extra planning to ensure production to run smoothly, the effort would have been compensated by the benefits to the supply chain. Figures 14 and 15 show the performance measurement outputs from Case $\mathrm{C}$. 


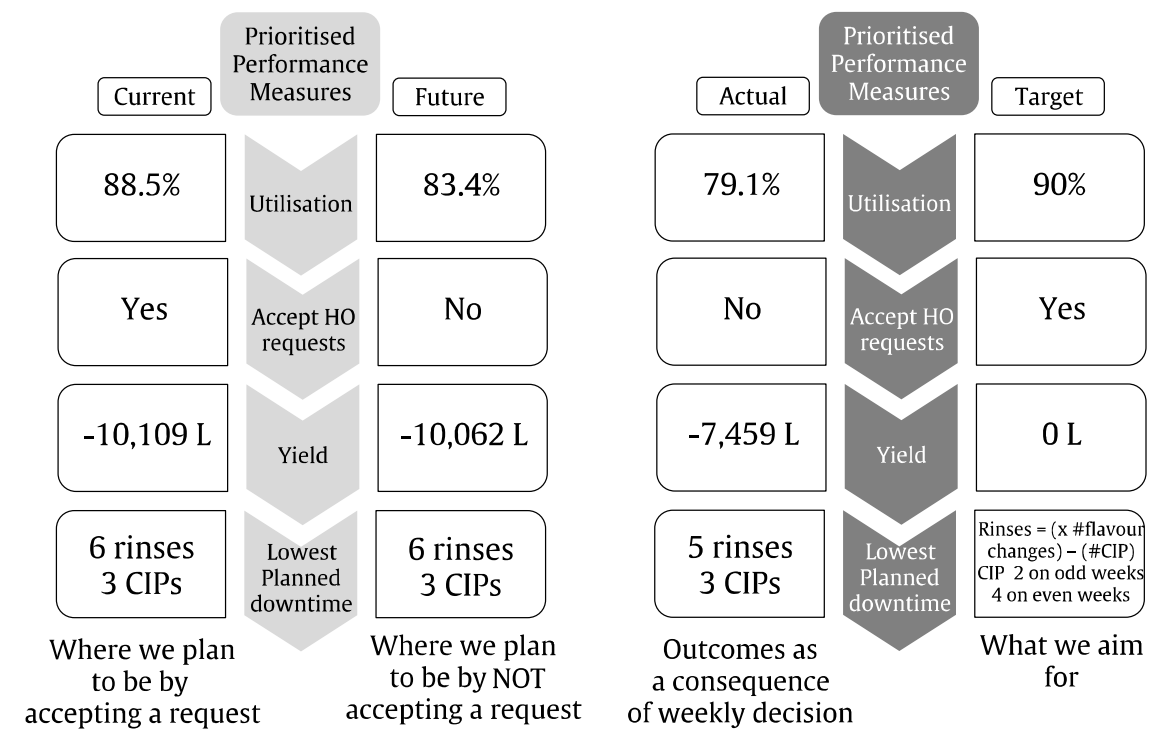

Figure 14: Performance Measurement data output from Case C

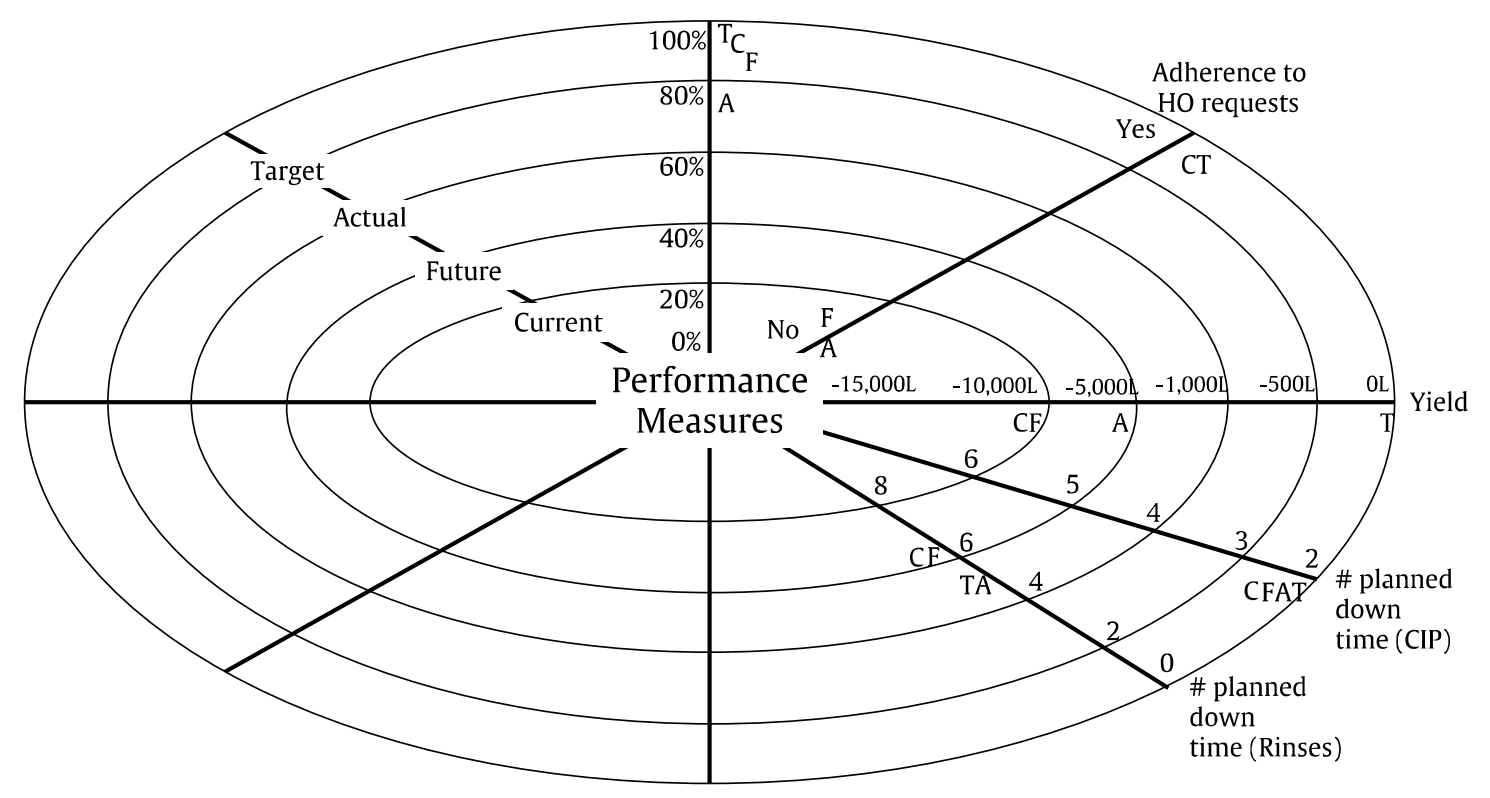

Figure 15: Spider-web chart of performance measure output from Case C

\section{Discussion}

After applying the framework to the case company and observing the impacts, the various components of the framework were analysed. Initially, the organisational flexibility equation model was discussed, followed by the supply chain and organisational alignment models. The framework was then examined. Finally the tools developed to test the framework were rationalised. Each section includes a critical analysis of the outcomes, with appropriate 
reference to previous findings, from the literature review as well as the case company. In this section, benefits and limitations are also considered.

This paper extends the contributions made by Pavlov and Bourne (2011) in the area of exante decision-making. The concept was initiated by Tang and Tomlin (2007) as a consequence of their research on the Triple-A framework. Further research has been carried out by Pavlov and Bourne (2011) who claimed that measurement has a dual role of acting as an ex-ante or ex-post information provider as well as guidance. No evidence has been found of ex-ante decision-making frameworks and thus the comparison to literature is based on the PMS instead.

The choice of basing the research project on a single case study was conscious but the project was adequate in order to gain an in-depth analysis of number of high level studies in several areas within the production line of a beverage company. The in-depth, single case study, nonetheless, has allowed the complexities of decision-making and PMS in a market leading fast moving consumer goods supply chain to be understood. However, the limitation to this approach is that the framework needs to be further tested in similar environments.

Academic researchers and industry experts alike have established that organisational flexibility is paramount for organisations to maintain competitive in todays' market (Tang and Tomlin, 2007). Researchers have suggested that in order to achieve organisational flexibility, PMS need to incorporate flexibility measures (Beamon, 1999). However, this research suggests that rather than solely incorporating the flexibility measures, the use of PMS as drivers to guide decision-making is what may lead to a more effective organisational flexibility. The guiding model developed in collaboration with the case company is simple enough to be accessible to those who may require it, although at this stage it has not yet demonstrated qualitative results.

Following recommendations to develop an integrated PMS that supports an integrated supply chain (Gunasekaran and Kobu, 2007), a framework of PMS that drives informed decisionmaking at an operational level has been created. This research project has considered what is known as one of the most significant paradigm shifts of modern business management; that individual organisations in a fast moving environment must do business as supply chains, so as to maintain competitiveness (Lambert and Cooper, 2000). It has also considered that the success of strategy fulfilment is highly dependent on the degree of alignment of performance measures, and that highlighting supply chain objectives and goals allows for associating 
targets at all levels (Akyuz and Erkan, 2010). This has often failed to occur in previous PMS (Holmberg, 2000). Furthermore, at the operational level, the different sections of the supply chain perform different activities. Some activities involve decision-making in the process. It is at this level that the aligned performance measures should be integrated.

The analyses of the findings have led to inferences that have been incorporated into the framework. They include, within a fast moving consumer goods supply chain, flexibility involves producing according to customer demand, which encompasses being agile to shortterm requests. This ultimately increases supply chain resilience (Tang and Tomlin, 2007). To accommodate short-term requests, the supply chain has to be able to make decisions not only at a strategic level, but also at a tactical and operational level. At an operational level, the department that makes decisions with a significant level of impact to the case company is the Production Planning Department. Short-term decision-making at an operational level implies making day-to-day decisions; some are in-house driven, e.g. due to material shortages and unplanned downtime; the head office, driven by customer demand, originates other requests. By proving that the process enables employees to make informed decisions, the acceptance of the change request can no longer be an ad-hoc decision.

It is widely acknowledged that complex decision-making environments typically involve a higher degree of uncertainty (McDaniels, et al., 1999). However, it is fundamental that individuals have adequate information and expert knowledge, as well as the required materials, to make choices (Kiker et al., 2005). For a fast moving consumer goods industry, adequate information implies the data are accurate and up-to-date (ideally real time). Studies have also shown that too many restrictions in decision-making activities tend to give negative effects (Berglund and Karltun, 2007). Provided flexible information technology tools are available and there are processes in place at an operational level, it is possible to optimise the decision-making process.

The decision-making process has been developed taking the previous factors into consideration. Financial and non-financial performance measures appropriate for production planning at the case company were contemplated in the testing phase. The framework has been developed to allow these measures to vary across the site and between organisations. This allows for the framework to be agile, as it can suit different areas of a supply chain. There is, however, a risk that the individual making the analyses of the performance 
measures' priorities may not have the required skills. Thus, it is important to provide the necessary training and to establish clear roles and responsibilities.

The developed decision-making framework allows individuals at an operational level to make decisions without having to micromanage or diminish their engagement. The tools are developed with a conscious decision not to provide the users with an answer, but rather with the adequate information that will enable them to make informed decisions. Testing for a longer period and a higher level of financial commitment would have been required to train employees to further assess the framework.

\section{Concluding remarks}

The framework proposed in this paper draws on the existing literature as well as the case study. It presents the resulting framework for decision-making at an operational level, which is ultimately intended to increase supply chain flexibility to customer demand. The formation is put forward as a framework for making informed decisions in a timely and accurate manner, applying PMS an innovative way. It is expected that the framework provides a ground to build numerous tools that practitioners can employ to gain a competitive advantage, by satisfying fluctuating customer demand whilst quantitatively considering the impact on the supply chain.

The framework responds to several key issues in the current research in performance measurement. Firstly, by commissioning organisational routines as one of its constructs, it provides a solid organisational foundation that is lacking in the existing performance measurement literature. Furthermore, by contemplating an alignment of performance measurement with the organisational strategy, the framework is balanced in every direction, be it strategic determinants, tactical performance criteria or on a metrics level.

\section{Acknowledgments}

The work reported in this paper is an outcome from a research project (grant number WR35201V) in collaboration with a global beverage company in the UK. The authors would like to thank Mr Steve Adams and Mr Mark Ebdon for their support.

\section{References}

Akyuz, G.K. and Erkan, T.E. (2010), "Supply chain performance measurement: a literature review", International Journal of Production Research, Vol. 11 pp.1-19. 
Angerhofer, B.J. and Angelides, M.C. (2006), "A model and a performance measurement system for collaborative supply chains”, Decision Support Systems, Vol. 42 No. 1, pp. 283301.

Beamon, M. (1999), "Measuring supply chain performance", International Journal of Operations \& Production Management, vol. 19, no. 3, pp. 275-292.

Berglund, M. and Karltun, J. (2007), "Human, technological and organizational aspects influencing the production scheduling process", International Journal of Production Economics, vol. 110, no. 1-2, pp. 160-174.

Bitton, M. (1990), "Méthode de conception et d'implantation de systèmes de measure de performances pour organisations industrielles [Method of Design and Implementation of Performance Measurement Systems for Industrial Organizations]." Thèse d'automatique, Université de Bordeaux I, France.

Bongsug, C. (2009), "Developing key performance indicators for supply chain: an industry perspective", Supply Chain Management: An International Journal, vol. 14, no. 6, pp. 422428.

Braz, R., Scavarda, L., and Martins, R. (2011), "Reviewing and improving performance measurement systems: An action research", International Journal of Production Economics, vol. 133 , no. 2 , pp. $751-760$.

Burgess, T.F., Ong, T.S. and Shaw, N.E. (2007), "Traditional or contemporary? The prevalence of performance measurement system types", International Journal of Productivity and Performance Management, Vol. 56 Iss: 7, pp.583 - 602.

Chapman, C. and Kihn, L.A. (2009), "Information system integration, enabling control, and performance", Accounting, Organizations and Society, vol. 34, no. 2, pp. 151-169.

Chiarini, A. and Vagnoni, E. (2015), "World-class manufacturing by Fiat. Comparison with Toyota Production System from a Strategic Management, Management Accounting, Operations Management and Performance Measurement dimension”, International Journal of Production Research, vol. 53, no. 2, pp. 590-606.

Collins, T. and Harris, H. (1992), "Productivity measurement: A shifting paradigm in purchasing”, NAPM Insights, vol. 2, pp. 10-11. 
Danese, P. and Romano, P. (2012), "Relationship between downstream integration, performance measurement systems and supply network efficiency", International Journal of Production Research, vol. 50, no. 7, pp. 2002-2013.

de Lima, E.P., da Costa, S.E.G., Angelis, J.J., Munik, J. (2013), "Performance measurement systems: A consensual analysis of their roles", International Journal of Production Economics, vol. 146, no. 2, pp. 524-542

Dixon, J., Nanni, A. and Vollmann, T. (1990), The New Performance Challenge: Measuring Operations for World-Class Competition, Business One Irwin, Homewood, IL.

Franco-Santos, M, Lucianetti, L. and Bourne, M. (2012), "Contemporary performance measurement systems: A review of their consequences and a framework for research", Management Accounting Research, vol. 23, no. 2, pp. 79-119.

Gomes, C., Yasin, M. and Lisboa, J. (2011), "Performance measurement practices in manufacturing firms revisited", International Journal of Operations \& Production Management, vol. 31, no. 1, pp. 5-30.

Grafton, J., Lillis, A. and Widener, S. (2010), "The role of performance measurement and evaluation in building organizational capabilities and performance", Accounting, Organizations and Society, vol. 35, no. 7, pp. 689-706.

Gunasekaran, A. and Kobu, B. (2007), "Performance measures and metrics in logistics and supply chain management: a review of recent literature (1995-2004) for research and applications”, International Journal of Production Research, vol. 45, no. 12, pp. 2819-2840.

Gunasekaran, A., C. Patel, and E. Tirtiroglu. (2001), "Performance Measures and Metrics in a Supply Chain Environment", International Journal of Operations \& Production Management 21 (1/2): 71-87.

Hall, M. (2008), "The effect of comprehensive performance measurement systems on role clarity, psychological empowerment and managerial performance", Accounting, Organizations and Society, vol. 33, no. 2/3, pp. 141-163.

Holmberg, S. (2000), “A Systems Perspective on Supply Chain Measurements”, International Journal of Physical Distribution and Logistics Management, Vol. 30, No. 10, pp. 847-868. 
Ilgen, D.R., Cynthia D.F. and Taylor, M.S. (1979), "Consequences of Individual Feedback on Behavior in Organizations", Journal of Applied Psychology 64.4: 349-371.

Kaplan, R. and Norton, D. (1992), "The balanced scorecard - measures that drive performance", Harvard Business Review, vol. 70, no. 1, pp. 71 - 79.

Kiker, G., Bridges, T., Varghese, A., Seager, T., and Linkov, I. (2005), “Application of multicriteria decision analysis in environmental decision making”, Integrated Environmental Assessment and Management, vol. 1, no. 2, pp. 95-108.

Kolehmainen, K. (2010), "Dynamic strategic performance measurement systems: balancing empowerment and alignment”, Long Range Planning, vol. 43, no. 4, pp. 527-554.

Koufteros, X., Verghese, A., Lucianetti, L. (2014), “The effect of performance measurement systems on firm performance: A cross-sectional and a longitudinal study", Journal of Operations Management, no. 32, pp. 313-336

Lambert, D.M., Cooper, M.C., (2000), "Issues in supply chain management", Industrial Marketing Management 29, 65-83.

Laudon, K and Laudon, J. (2014), "Management Information Systems: Managing the Digital Firm, $13^{\text {th }}$ Edition, Pearson Education Limited, Harlow, England.

Manikas, I. and Terry, L. (2010), “A case study assessment of the operational performance of a multiple fresh produce distribution centre in the UK”, British Food Journal, vol. 112, no. 6, pp. 653-667.

McDaniels, T., Gregory, R. and Fields, D. (1999), "Democratizing risk management: successful public involvement in an electric utility water management decision", Risk Analysis, vol. 19, no. 3, pp. 491-504.

Moullin, M. (2007), "Performance measurement definitions: Linking performance measurement and organisational excellence", International Journal of Health Care Quality Assurance, Vol. 20 Iss: 3, pp.181 - 183

Mundy, J. (2010), "Creating dynamic tensions through a balanced use of management control systems", Accounting Organizations and Society, vol. 35, no. 5, pp. 499-523. 
Najmi, A. and Makui, A. (2012), "A conceptual model for measuring supply chain's performance, Production Planning \& Control: The Management of Operations”, vol. 23, no. 9, pp. 694-706.

Neely, A., Mills, J., Gregory, M. and Platts, K. (2005), "Performance measurement system design-a literature review and research agenda", International Journal of Operations and Production Management, vol. 15, no. 4, pp. 80-116.

Pavlov, A. and Bourne, M. (2011), "Explaining the effects of performance measurement on performance: An organizational routines perspective", International Journal of Operations \& Production Management, vol. 31, no. 1, pp. 101-122.

Poon T., Choy, K., Chan, F. and Lau, H. (2011), “A real-time production operations decision support system for solving stochastic production material demand problems”, Expert Systems with Applications, vol. 38, no. 5, pp. 4829-4838.

Saaty, T.L. (1990), "How to make a decision: the Analytic Hierarchy Process", European Journal of Operational Research, vol. 48, pp. 9-26.

Schuff, D., Paradice, D., Burstein, F., Power, D. and Sharda, R. (2010), Decision Support: An Examination of the DSS Discipline, Springer, Stillwater, OK.

Shepherd, C. and Günter, H. (2006), "Measuring supply chain performance: current research and future directions", International Journal of Productivity and Performance Management, vol. 55 no. $3 / 4$, pp. $242-258$.

Tang, C. and Tomlin, B. (2007), "The Power of flexibility for mitigating supply chain risks", International Journal of Production Economics, vol. 116, no. 1, pp.12-27.

Tang, C. and Tomlin, B. (2008), "The Power of flexibility for mitigating supply chain risks", International Journal of Production Economics, vol. 116, no. 1, pp.12-27.

Taticchi, P., Garengo, P., Nudurupati, S.S., Tonelli, F., Pasqualino, R. (2014), “A review of decision-support tools and performance measurement and sustainable supply chain management", International Journal of Production Research, DOI: $10.1080 / 00207543.2014 .939239$ 
Tayler, W. (2010), "The balanced scorecard as a strategy-evaluation tool: the effects of implementation involvement and a causal-chain focus", The Accounting Review, vol. 85, no. 3, pp. 1095-1117.

Taylor, A. and Taylor, M. (2014), "Factors influencing effective implementation of performance measurement systems in small and medium-sized enterprises and large firms: a perspective from Contingency Theory", International Journal of Production Research, vol. 52, No. 3, pp. 847-866.

Veen-Dirks, P. (2010), "Different uses of performance measures: The evaluation versus reward of production managers", Accounting, Organizations and Society vol. 35, no. 2, pp. 141-164.

Verdecho, J., Alfaro, J. and Rodriguez-Rodriguez, R. (2009), "Foundations for collaborative performance measurement”, Production Planning \& Control, vol. 20, no. 3, pp193-205.

Witcher, B.J. and Chau, V.S., (2007), "Balanced scorecard and hoshin kanri: dynamic capabilities for managing strategic fit”, Management Decision, Vol. 45, Iss: 3, pp. 518 - 538

Wouters, M. and Wilderom, C. (2008), "Developing performance-measurement systems as enabling formalisation: A longitudinal field study of a logistics department", Accounting, Organizations and Society, 33, pp. 488-516.

Zhaofang, M., Li X, and Fu, J. (2006), “A new Approach of Supply Network performance measurement based on Supporting level and operational level", Proceedings of the Technology and Innovation Conference, 2006. ITIC 2006. 6-7 Nov. 2006, pp. 1537-1545. 